\title{
Blended Learning as an Effective Mean to Increase Motivation for Studying English as a Second Language
}

\author{
Irina Malinina \\ National Research University Higher School of Economics
}

\begin{abstract}
Application of Web-related technologies opens up new opportunities in arranging educational environment. Web 2.0 provides resources and tools that make learning process social and collaborative as they connect students with each other and help to move from instructor-centred methods of teaching to more contextual learning and problem-solving techniques. As students always expect activities and content to be relevant to the real world it gives them an additional incentive to study. Moreover, Web-related technologies contribute to the individualisation of education, as they allow to study at one's own pace, at convenient time, in a suitable place. As a result, students are more motivated and encouraged to study. Application of information technologies lets learn, practise and revise in a new, more interesting, exciting and, consequently, effective way. The majority of Web-based tests can assess the work and what's even more important students get the feedback on their answers, so they have an opportunity to correct mistakes. Live communication also plays an essential role in education, as gives rise to emotions, increases motivation, improves communicative culture, promotes personal and professional growth.
\end{abstract}

\section{Introduction}

Application of information technology in many spheres of human activity including education is a distinctive feature of the development of the modern society. Speaking about graduates of institutions of higher education we mean not just a professional in a particular area, but a cultural, educated, creative person who is not only able to use data and information and communication technologies (ICT) in his or her work, but also willing to take advantages of them in maintaining and developing own intellectual and creative potential.

In order to reach this aim of higher education it is necessary to create conditions and arrange educational environment in the way that will provide the required level of training. Moreover, it is of equal importance to manage the educational processes.

This aim forces the changes in requirements for contents, approaches, methods and techniques of education and, as a result, for teachers, because they determine to a very large extent the quality of training. The main role of a teacher is to arrange educational environment, provide students with necessary materials, support and encourage them. One possible way to do it is to combine online and Face-to-Face teaching.

There is a good saying: "English is not a subject that can be taught, it is the subject that must be learnt", especially if you are going to study it as a second language, so, it is necessary to be prepared that it will take a lot of time and effort. It means that much depends on students, their willingness and motivation to study.

Global integration has led to the expansion of international contacts in all spheres of human life, including education. An increasing number of students prefer to study at a foreign university nowadays. Some choose short-time programs, while others prefer bachelor or master programs or even getting $\mathrm{PhD}$ abroad. But not everyone can integrate both academically and socially successfully. In comparison with domestic students, international learners need to pay additional attention and effort to social integration, as their family, friends from their home country are mostly not within an easy reach. It has been proved by educational psychology that the role of the family on the attitudes and motivation of students has been significant. So, study- and social support by family and friends have a positive influence on academic performance. Social networks such as Facebook, Twitter provide opportunities for meeting new people, making friends, finding and sharing necessary information, getting acquainted with lifestyle and traditions of other nationalities, as well as keeping in touch with family and childhood friends, which, as a result, lead to an increase in motivation and satisfaction with academic environment.

English is an international language, so it is spoken all over the world, a lot of people use it as the second, third and even forth language, bringing special 
features, words and peculiarities of their own cultures. Nowadays it is not enough to know only customs and traditions of English-speaking countries, as international teams are widely-formed and your potential partners are likely to be citizens of different states. More recently, non-English speaking countries are increasingly attracting foreign students. Special attention should be given to forming qualities such as politeness, tact, courtesy, tolerance, since they, along with erudition and education are the basis of communicative culture. These qualities are very useful in overcoming difficulties related to lack of language and culture knowledge, as courtesy and tolerance are not only respected everywhere, but also help to respond adequately to new and "strange" things and behaviour and deal with cultural stereotypes. Knowledge of a foreign language does not necessarily lead to successful social interaction, because understanding of the culture and skills in intercultural communication can be even more important. They say: "When in Rome, do as Romans do". That's why learning a foreign language involves getting acquainted with national customs and traditions, mentality and culture of the country where this language is spoken. Sociocultural competence is a key to successful intercultural communication, as it assumes awareness of social factors' influence on the choice of linguistic forms, appropriate words and knowledge of ethical behaviour. So, it is better to form it with the help of sociocultural approach to learning. Sociocultural approach is traditionally considered as an interconnected learning of the language and culture of native speakers. However, to limit the language training by learning the culture of only the target language country is unjustified. Studying native culture should be an equal component in mastering the art of intercultural communication. Learning a foreign language culture should have a comparative nature and include links to the native culture, so as to be "a dialogue between the two ways of life and thought".

\section{Blended Learning}

In 2003 the American society for training and development announced blended learning one of the ten top trends in the knowledge delivery industry. Almost ten years later the term "blended learning" is frequently used in education-related fields.

Blended learning is the term used to describe learning or training events or activities where e-learning, in its various forms, is combined with more traditional forms of training such as "class room" training [6].

Another definition of blended learning is "any time a student learns at least in part at a supervised brickand-mortar location away from home and at least in part through online delivery with some element of student control over time, place, path, and/or pace." [7] In reviewing the literature, many suggest that blended courses emerge "where between 30 to 79 percent of the instruction is delivered online". But online teaching is a complement to on-campus teaching and not a replacement [8].

According to David Nagel there are six models of blended learning:

1. The "face-to-face driver" model, in which a teacher in a traditional classroom instructional setting employs online learning for remediation or supplemental instruction;

2. The "rotation" model, in which students move back and forth between online and classroom instruction;

3. "Flex", a model in which the curriculum is delivered primarily through an online platform, with teachers providing onsite support;

4. The "online lab" approach, wherein an online course is delivered in a physical classroom or computer lab;

5. "Self-blend", a model in which students choose on their own which courses they take online to supplement their schools' offerings;

6. The "online driver" model, where the courses are primarily online and physical facilities are used only for extracurricular activities, required check-ins, or similar functions [6].

Alan Clarke gives another variety of forms in blended learning:

1. Conventional lecture with teaching notes and visual aids placed on a college intranet for you to access.

2. Using digital cameras to record practical work for your portfolio of evidence.

3. All assignments submitted in an electronic format and feedback provided in the form of annotation.

4. Email and conferencing with tutors in place of faceto-face tutorials.

5. Simulations of laboratory experiments as part of a conventional/ science course.

6. Distance learning course with regular face-to-face meetings [2].

In order to choose the most suitable variant it is necessary to consider several factors including:

- Students

- Teachers

- Time

- Money

- Goals

- Resources [6].

\section{The Role of a Teacher}

The main characteristics of a modern educator are deep knowledge of the subject, scholarship, curiosity, pedagogical skills, communicative culture, willingness and ability to implement into the learning process methods and technologies providing constant 
development of students, encouraging the growth of their creativity and initiative.

Nowadays the list of professional skills of teachers includes different abilities, for example,

A ability to design their own training technologies;

A ability to independently and efficiently resolve constantly arising difficulties and challenges;

A ability to develop and use non-standard methods of solving educational problems;

A ability to rationally evaluate their own professional work and put achievable goals.

The ability to analyze their own teaching activities is of high priority as well, as it helps to correct, improve and match them to modern requirements. Moreover, it allows to identify teachers' own strengths, weaknesses and opportunities and, as a result, to create a strategy to improve the level of professional work and to contribute to the development of the personal qualities of the teacher.

Teaching involves performing several functions teaching itself, educating, organizing and researching. Professional activity of the teacher will be ineffective if it is built for the fulfillment of only one function. This activity is defective because it does not exploit opportunities to achieve higher educational outcomes, but also because it does not contribute to the development of the personality of the teacher.

The most favorable condition for professional and personal growth is a combination of various activities. Only those teachers who constantly improve their work and develop their skills will be able to provide the required level of training.

It is a well-known fact that objectives of education can be achieved using various methods and techniques. It is necessary to keep in mind that only their combined use will lead to success in the educational process. The choice should be made on the basis of purposes and tasks of learning; the level of knowledge is also important. Choosing a method of training the teacher considers different factors such as time determined for the study of this topic, role and significance of educational material for further professional or learning activity of students, available resources and tools, equipment, etc.

Selecting the material it is important to draw students' attention to ethical issues, social responsibility, cultural aspects. All these issues are acute nowadays, but solved differently in different counties. And in our international world it is necessary to know, value and respect customs and traditions, various ways and styles of life in other states.

So, to sum it up, it is vital to remember that training is not only mastering of knowledge and skills, but also development of both students and teachers. In this double-sided process the main function of a teacher is to arrange educational environment and provide students with necessary materials. The best way to do it is to combine the use of online resources with face-toface teaching.

\section{Application of ICT}

Application of ICT opens up new opportunities in arranging educational environment. The new Web provides resources, tools and technologies that can make educational process social as they help create collaborative learning atmosphere.

For example, tricider.com [15] is an excellent tool for brainstorming and sharing ideas. Besides, it can be used to vote for or against the suggested idea and give your arguments.

What is great about using a tool like this is it makes learning experience social as it connects students with each other. Moreover, it teaches students to work in a team, listen to, agree, disagree, convincingly prove their points of view, give reasons and make conclusions.

Tricider.com can be used as a preparation for a role play or other methods of active learning. As a home assignment a teacher may ask students to find the way out of the problem faced by the company or corporation. After brainstorming students suggest the solutions of the problem and then in the class they are acquainted with the way of resolving this dilemma, which actually took place.

Thus, this method of training helps to increase motivation to learning, because the awareness of students that they not only analyze the problems related to their profession, but also discuss the real events, allows them to believe in themselves and provides an additional incentive to study. Students always expect activities and content to be relevant to the real world [1].

So, tricider.com promotes interaction and collaboration of students and helps to move from instructor-centred methods of teaching to more contextual learning and real-world problem-solving techniques [9].

Learning a foreign language involves getting acquainted with national traditions, mentality and culture of the country where this language is spoken. Lack of language environment can be compensated with the help of authentic texts that demonstrate different aspects of the life of another nationality (cultural, social, domestic, economic, etc.) and promote the understanding of the language in the way native speakers use it. Various in style, grammar, topics authentic texts illustrate the functioning of the language in a natural social context and allow students to easily adapt to the individual manner of speech and as a result help intercultural communication.

Modern ICT let present new material on a higher 
level. Speaking about learning a foreign language it is difficult to overestimate the role of ICT. Can a blackand-white script of a dialogue be comparable with a video conversation?! Besides, a student can stop the recording when they want, watch and listen to any part of the conversation as many times as necessary and what is also very important students get acquainted with the body language. It is very useful to give tasks on the interpretation of facial expressions and gestures of native speakers and recognition of their relationship's style (formal, informal, friendly and so on).

So, application of ICT, on the one hand, contributes to the individualisation of education, as it allows to study at one's own pace and, on the other hand, is an effective means of forming communicative culture of the students. The latter is of vital importance due to the global integration.

ESLVideo [11] is a great tool of video based quizzes. Here there is a choice to create your own quizzes, you can ask as many multiple choice type questions as you wish or use available ones. It is possible to add transcripts, translation or notes to the video. What is also great is that the site can assess the work: students get the feedback on their answers and then their results are sent to the teacher (if the class are registered users of the site), so it can be done at home. Or a teacher may get students to create quizzes for each other as a hometask.

Speaking about teaching phonetics the role of ICT is also significant. It is possible to record your own pronunciation and compare it with the standard. Almost all modern dictionaries have audio translation and it is very useful in order not to make mistakes when speaking with people of other cultures (as different pronunciation always worsens understanding).

Moreover, there are sites that can be used for teaching pronunciation with different purposes. For example, forvo.com [12] is a multilingual pronunciation dictionary; words are recorded by the users of the site. You can get the general information about the person who recorded the word; also you can add your own pronunciation. What is especially good about this site is that you can get a wonderful collection for comparing accent.

The purpose of another audio tool voxopop.com [16] is to record your own speaking for others to listen and respond to [7]. It is excellent for real communicative speaking and listening practice out of the classroom. This site can be used for writing dictations as well, when a teacher records a dictation text and gets students to write it down. It is also a great tool to record and practise pronunciation drills, which are very useful when studying a foreign language.

Students who wish to be a success in life should learn to acquire knowledge using different kinds of learning systems and platforms. Moreover, online learning can help teachers to save time while at the same time increase their offerings to students. Web-related communication technologies, such as Quizlet [14], let learn words in a new, more interesting, exciting and, as a result, effective way. It is well-known that it is impossible to master a foreign language without constant exercising and drilling. And Quizlet is of great help here, as it allows in a playful manner to practise words and word combinations.

Depending on the objectives and available time the teacher can use ready-made cards, as now there are more than 9 million sets of topics to choose from. Another way is to tailor cards to suit the requirements of educational programs or create own sets paying attention to the needs of a particular group of students, their level of knowledge and experience. It goes without saying that cards specially tailored for a certain group always give better results, as while making them teachers take into account characteristics of students, their preferences and needs. So, with the help of Quizlet.com it is rather easy and very convenient to approach individually to each group and even to a particular student.

Another advantage of using ICT in teaching English is the opportunity of working with tests. Almost all textbooks have already developed tests. The only thing the teacher has to do is to download them. The system will check them, paying attention to the number of attempts and time needed to complete the test of each student.

Web-related tool Cloze test creator [13] is excellent for revising and testing. You can upload any text and choose what exactly you want to check. The choice is every n-word, articles, prepositions, link words, auxiliaries, wh-words, quantifiers or modals. You can also add clues if you wish.

Another tool that can be used for revising is Wordle [17]. What is especially great about this site is that it creates colourful graphic representations of the texts. To add to this, it is possible to edit the text: to delete any word, select the text direction, change colours or fonts. Another task Wordle can be suitable for is drilling grammar, for example Past Tenses. If you want to make drilling more interactive and social you can use a stickman [10]. Practising prediction, for example, in a playful manner could be more effective.

Another important skill nowadays is the ability to make presentations. And again ICT are very useful here. Due to the goal and time available to achieve it presentations can be demonstrated during the lesson or the teacher can download them (for examples, from YouTube) and students will have an opportunity to watch them at home as many times as needed in a relaxed and comfortable atmosphere. The teacher may prepare the questions beforehand, such as: While delivering the 
speech did the presenter remember to face the audience and make eye contact with them? Was he/she logical? Did he/she emphasise key words? When presenting a detailed argument, were facts and figures used to support the ideas? Did the presenter use approximate or rounded figures? Were visuals very useful? etc. With the help of these questions the teacher can draw students' attention to various means that can make presentations effective, easy to follow and understand.

Implementation of learning management system (LMS) allows teachers to monitor the learning activities of students. Moreover, it helps to communicate teachers and students, to make announcements, determine the time for examinations, set deadlines, get quick responses and feedback from students. Some LMS, for example Moodle, Blackboard, have built-in wiki tools, which are designed to collaborate, share and build online content and are especially useful for learners who are separated by time and place. Wikis are more effective for forwarding information compared to emails attachments with tracked changes, a method that supports only one editor at a time and can create issues with students having multiple and conflicting versions of the same document [5].

Using a variety of methods, techniques and tools the educator tries to build students' interest in the very process of communication. It is necessary to draw students' attention to the logic of the narrative, introduction and conclusion, usage of linking phrases. The teacher should be ready to come to help using leading questions, prompting the required word, assisting in completing the thought. All these contribute to overcoming the psychological barrier and increasing communicative activity, which is necessary to learn the art of communication [4].

The teacher should remember that education, as well as any other activity has not only cognitive aspects, but live communication also plays a huge role, which gives rise to emotions, feelings, promotes personal and professional growth. The teacher should try to find an individual approach to each student and create an environment of psychological comfort in the educational process. First of all it concerns the skill of teachers to dialogue, since the presence of communication barriers leads to a decrease in the quality of education and demotivation.

\section{Research and results}

Before starting our pilot project on implementing blended learning into educational process we provide students with information about educational strategy, corporate culture of the university, requirements for the level of knowledge both in English and computer technologies, aims and objectives of learning as well as methods and techniques used to achieve them.

At the beginning of our educational program students were presented with some questionnaires in order to gather information about their motivational state and their attitude to introducing ICT. We wanted to research each student's motivation of success and fear of failure and to assess their willingness to implement ICT into educational process and their expectations.

Our educational program was designed for participants of the Presidential Program for Senior Level Managers of the Russian Federation in The National Research University Higher School of Economics in Nizhny Novgorod. 42 participants took part in our program, all of them are from different backgrounds: they have graduated from different universities and work for different companies in various areas of industry.

According to the received answers of our questionnaire about their expectations of the content and the aim of the English Language course, the majority of the respondents would like to improve their communication skills (86\%), and 62\% want the training to be relevant to their job-related activities.

Another questionnaire and some interviews were conducted in order to find out the attitude to introducing ICT in educational process among participants. At the end of the program, the same questionnaire and interviews were presented once more to gather more information about the participants' motivational state, their attitude to ICT. It is worth mentioning that in order to minimize the possible negative affect of the lack of computer skills before starting to implement each tool or recourse we provide our students with detailed information on their using and always give time to the acquaintance with the basic elements of the user interface program.

At the end of the program the attitude to using ICT has changed towards the positive impact on the results of training. The participants were very willing to continue using Web-related technologies to improve their language skills and all of them admit that these tools are useful, helpful and practical (especially eslvideo.com and voxopop.com).

Another question we would like our students to answer was about the desirable way to study English. The received responses show that the majority of learners $(98 \%)$ want to study English with the teacher, but they expect to be approached individually (76\%). During interviews they explained that it is very important for them that their characters, peculiarities and the level of knowledge should be taken into account. Another positive aspect they indicate in blended learning is that it allows to train necessary skills at a convenient time wherever they want. Moreover, they can interact with each other in a more comfortable (than email) and less intrusive (than 
telephone call) way.

So, to sum it up, participants of blended learning program considered it efficient, useful and beneficial, but the key role in their opinions is played by the teacher who designs the courses, directs the learning activities of students, motivates and encourages them.

\section{Conclusion}

Finally, it is important to underline that there is not a single strategy how to achieve the desirable aim in education. Each teacher should use various methods and techniques, constantly explore new opportunities, study, develop their skills and abilities. It is necessary to remember what worked perfectly yesterday might now seem not only old-fashionable, quaint, but also ineffective and inefficient.

So, in order to "survive" it is essential to be flexible, to adapt to changing conditions, develop and be in a continuous search for new approaches, ways and tools that can be useful in satisfying cognitive aspects of education, increasing motivation and productivity of learning. But it is necessary to remember that ICT are only means (certainly, very effective and powerful) that can be very useful for reaching the aim of education. Teachers should not forget about classroom communication, as education is not only studying, but also upbringing and development. Therefore, it is vital to choose the correct material (text, audio, video) in order to draw students' attention to ethical issues, social responsibility, cultural aspects and so on. Thanks to ICT it is easier to achieve this purpose of education as well.

It would be a great idea to provide some introduction programs, to give some information about educational culture of the university to foster academic adjustment of new students.

Nowadays it is impossible to imagine educational process without online learning. Various web-related communication technologies, learning management systems help teachers save time and increase their offerings to students, increase students' motivation and enhance their academic and social integration.

\section{References}

[1] Beldarrain, Y. (2006) "Distance education trends: Integrating new technologies to foster student interaction and collaboration". Distance education, 27(2), pp. 139-153.

[2] Clarke, (2004) A. e-learning skills. Palgrave Macmillan, $258 \mathrm{p}$.

[3] Lightner, S., Bober, M., and Willi, C. (2007) "Team-based activities to promote engaged learning". College Teaching, 55(1), pp. 5-18.

[4] Malinina, I. (2012) "Blended learning of the
English language: combining online and face-to-face teaching" in Proceedings of London International conference on education (LICE-2012) Infonomics Society: London, UK, pp. 247-251.

[5] Richardson,W. (2006) Blogs, wikis, podcasts and other powerful Web tools for classroom. Thousands Oaks, CA: Corwin Press.

[6] Peachey, N. (2012) An overview of blended learning, $32 \mathrm{p}$.

[7] Peachey, N. (2012) Web 2.0 tools for teachers, 53 p. [8] Watwood, B., Nugent, J., Deihl, W. (2009) Building from content to community: Rethinking the transition to online teaching and training. White paper. VCU Center for teaching excellence, $22 \mathrm{p}$.

[9] West, James A., West, Margaret L. (2009) Using wikis for online collaboration. The power of the readwrite web. Wiley Imprint, $142 \mathrm{p}$.

[10] www.drawastickman.com/ (Access date: 20 April 2013)

[11] www.eslvideo.com/index.php (Access date: 26 April 2013)

[12] www.forvo.com/ (Access date: 27 April 2013)

[13] www.l.georges.online.fr/tools/cloze.html (Access date: 20 April 2013)

[14] www.quizlet.com/ (Access date: 27 April 2013)

[15] www.tricider.com/ (Access date: 23 April 2013)

[16] www.voxopop.com/ (Access date: 27 April 2013)

[17] www.wordle.net/ (Access date: 27 April 2013) 